\title{
Biological study of Hyles euphorbiae L. (Lepidoptera:Sphingidae) in Kurdistan Region, Iraq
}

\author{
Hana H. Mohammed ${ }^{1}$ and Mohammed S. Abdul-Rasoul ${ }^{2}$ \\ ${ }^{1}$ Biology Department, College of Science, University of Salahaddin, Erbil, Kurdistan Region of Iraq \\ ${ }^{2}$ Baghdad Natural Musem, Baghdad, Iraq
}

\begin{abstract}
The leafy spruge hawk moth H.euphorbiae is monophagous insect feed on different species of the genus Euphorbia. The biology of $\mathrm{H}$. euphorbiae was studied in detail during May to November under laboratory conditions. The development of egg, larva, pre-pupa and pupal periods occupied $9.42 \pm 1.65$, $20.31 \pm 2.08,2.67 \pm 0.37$ and $57.10 \pm 5.97$ days, respectively. Total life cycle was 89.5 \pm 10.1 .The sex of $H$. euphorbiae can be determined during pupal stage, in the male there are two small points at the fifth segment, while in females there's a line at the same position. Adults became active in the night .All mating observed among caged adults occurred at night. The longevity of the female ranged from 11-16 days with an average of $13.86 \pm 1.73$, while in case of male it was 8-11 days with an average of $10.55 \pm 1.00$
\end{abstract}

Keywords - Hyles euphorbiae, Euphorbia macrocalda

\section{INTRODUCTION}

The spurge hawk moth Hyles euphorbiae L. (Lepidoptera: sphingidae) is a large hawkmoth species distributed in Central/Southern Europe and Western Asia [1], it is a large insect, strong fliers and are active nocturnally.The adult measures 2 to 3 centimeters long with a 5 to 7 -centimeter wingspan ,body is olive brown with white and black markings. The forewings are patterned with olive brown; the hind wings are pink with black markings. The leafy spurge hawkmoth, completes one and sometimes two generations per year and requires 42-72 days to complete development this is dependent on temperature and food source. The Firstgeneration adults emerge in early to midsummer; if a second generation of adults occurs, it will do so sometime from late August through September, There're five life stages: egg, larva, pre-pupa, pupa and adult. Firstgeneration larvae can be found during June; if a second generation occurs, it will in August. The larvae are large caterpillars that have a "caudal horn at the back, dorsally, on the 8th abdominal segment. Mature fifth-instar larvae drop to the ground and enter the soil to pupate. [2]

The food plants restricted to the genus Euphorbia and occasionally a single record on a plant species in an unrelated family which include different species of the genus Euphorbia (Euphorbiaceae). When damaged, leafy spurge exudes milky latex that discourages grazing by most wildlife and domestic cattle and horses. The latex contains "ingenol," a toxic compound that is highly inflammatory and emetic to most mammals, including humans. The latex causes scours and weakness in cattle and may result in death [3].The genus Euphorbia is chemically defined by the occurrence of a large number of polyfunctional diterpenoids with the tigliane (phorbol), ingenane and daphnane skeletons most of them are skin irritants and toxic [4].

The caterpillar of $H$. euphorbiae does not actively sequester phorbol esters, their aposematic colouration could be based on chemical defence mediated by phorbol esters quickly present in their gut. These hawkmoth caterpillars have a large gut full of plant material, which they regurgitate into the direction of the predator when attacked in nature [5].

Several studies were undertaken in Nebraska, some of these studies involved the life cycle of the $\mathrm{H}$. euphorbiae and its feeding behavior. Yet, there's no biological and ecological research was done in Iraq except the first known observations on the hawkmoth H. euphorbiae., of Iraq are those reported by [6] in 1957.

The aim of the present paper is study the life cycle of H. euphorbiae to provide a starting point for further studies by pulling together the various ecological and to determine the effectiveness of the spurge hawkmoth as a biological control agent for leafy spurge in Kurdistan Region of Iraq.

\section{MATERIAL AND METHOD}

The larvae of H. euphorbiae were collected and reared on Euphorbia macrocalda for the maintenance of pure culture in the laboratory. The larvae were kept in the room temperature during the experiment. Cotton wad dipped in 10 per cent honey solution was provided as food for the moths. The eggs laid were counted daily till the death of female moth. Freshly laid eggs were kept on leafy spruge leaf in Petri plates provided with wet blotting paper at the bottom to protect the eggs from desiccation. After hatching larval instars were studied by transferring them to the plastic containers with the help of camel hair brush. The fresh leafy spruge leaves were provided as food for developing larvae, duration of instars and pupal duration was recorded. As measurements 
were taken each day, it was possible to note the number of days each larva spent as a particular instar by skin color changes of the larvae and molted head capsule. These observations were recorded with the consumption data for each larva.

\section{RESULT AND DISCUSSION}

1- Egg: Females lay small groups of eggs on upper surface of new foliage of leafy spurge in a clusters of 64 122 eggs, the eggs are light green to yellow spheres. The surface of the egg was smooth, shining and covered with liquid gum, which enables them to stick on the small leaves of the spruge. The incubation period lasted for 7 to 12 days with a mean of $9.2 \pm 1.92$ days. Egg measured from 1.76 to $1.99 \mathrm{~mm}$ length with an average of $1.86+0.08 \mathrm{~mm}$. The present observation on egg laying is somewhat in conformity with [2] that females oviposit 150 light green spheres, $1 \mathrm{~mm}$ diameter egg singly or in clusters on leaves and bracts of the spurge plants .Spurge hawkmoth lay egg in cluster on average 162 eggs per individual with incubation period of $9 \pm 0.5$ in laboratory condition [7].

2- Larvae: Had five instars. The caterpillar moulted for four times completing five larval instars. Duration occupied by each instar on leafy spruge is presented in the (Table 1). The length and size of the head capsule increased as the larval stages advanced. Maximum length and head capsule width was observed in fifth instars (Table 2).

2-1 First instar: Neonate larva was tiny, cylindrical with dark body and head with innumerable whitish dots. The median dorsal horn present on the $8^{\text {th }}$ abdominal segment was yellowish in colour and posture was vertical to the body. No colour change was observed in the first instar larvae. First instar lasted for 4 to 5 days with an average of days $4.56 \pm 0.35$. First instar larvae measured 3.7 to 7.6 with an average $5.97 \pm 1.18 \mathrm{~mm}$ and head capsule width was 0.76 to $0.78 \mathrm{~mm}$ with an average of $0.77 \pm 0.01 \mathrm{~mm}$. The Larvae are very sociable and packed together on the Spurge leaves. Larvae fed on the leaf tissue by scraping the chlorophyll content of epidermis and as age advanced it made small holes on the leaves, the same observation was shown by of Agrius convolvuli on greengram leaf [8].

2-2 Second instar: Remarkable change in the body color was observed. All larvae colouration was changing rapidly and taking on a more Yellow background color and blackish blotches which inside were dotted with white. They were starting to look rather beautiful. Second instar lasted for 2 to 3 days with an average of $2.54 \pm$ 0.35 . The larvae started feeding from the margin of the leaves. Second instar larvae measured 12 to $18 \mathrm{~mm}$ in length with an average of $15.51 \pm 2.04 \mathrm{~mm}$; head capsule width was 1.16 to $1.31 \mathrm{~mm}$ with an average of $1.26 \pm 0.04 \mathrm{~mm}$.

2-3 Third instar: Larvae increased in the size with nearly vertical horn. The horn was thick, yellow at the base and black tapering at the end. Third instar occupied 2 to 3 days with an average of $2.58 \pm 0.37$ days. Third instar larvae measured 22 to $27 \mathrm{~mm}$ in length with an average of $25.08 \pm 1.62$.

2-4 Fourth instar: The larvae showed their final colour pattern. Larvae have a distinctive red, black, yellow, and white color pattern, set in a ground colour which varies from yellowish to black; the head coral-red colour, and a line of the same colour runs all along the back, from the head to the horn. Horn had red base with black tip. This instar lasted for five to seven days with an average of $5.45 \pm 0.68$ days and $5.70 \pm 0.67$. Fourth instar larvae measured 46 to $58 \mathrm{~mm}$ in length with an average of $50.16 \pm 3.85 \mathrm{~mm}$ and head capsule width 3 to 3.1 $\mathrm{mm}$ with an average of $3.06 \pm 0.05 \mathrm{~mm}$.

2-5 Fifth instar: The fifth instar larva was very active and fed hungrily and the leaves were completely devoured including veins. Fifth instars occupied 6 to 7 days with an average $6.53 \pm 0.34$ days. Fifth instars larvae measured 85 to $99 \mathrm{~mm}$ in length with an average of $94.60 \pm 4.03 \mathrm{~mm}$ and head capsule width was 5 to 5.2 $\mathrm{mm}$ with an average of $5.05 \pm 0.08 \mathrm{~mm}$ diameter. This result agree with [9] who observed that fifth instar larvae of Daphnis nerii was measured $85 \mathrm{~mm}$ in length .

2-6 Total larval period: $H$.euphorbia occupied 17 to 23 days with an average of $20.31 \pm 2.08$ days to become full grown larva (Table 3). This result is somewhat agree [7] who observed larval development period of $H$. euphorbiae was $19 \pm 2$ days. A. convolvuli had five instars occupying on an average $24.85 \pm 2.33$ days with a range of 21 to 30 days on greengram [8].

3- Pre-pupa: Fully grown larvae stopped feeding and wriggled inside the remaining glued leaves. The body size gradually shortened became rough enough inside the case, and entered pre-pupal stage. The pre-pupal stage occupied 2 to 3 days with an average of $2.67 \pm 0.37$ (Table 3). Pre-pupal length varied from 80 to $85 \mathrm{~mm}$ with 
an average of $82.92 \pm 1.36 \mathrm{~mm}$ (Table 1). This result agreement with [8] who observed pre-pupa 1 period of $A$. convolvuli varied from 2 to 3 days with an average of $2.90 \pm 0.73$ days on greengram.

4- Pupa: Light brown with fine, dark striations. pupa formed within a net-like cocoon, incorporating leaves, and other debris. The time spent in this stage can vary considerably from 44 to 65 days with an average of 57.10 \pm 5.97 (Table 3). Pupal length varied from $50-55 \mathrm{~mm}$ with an average of $52.67 \pm 1.65 \mathrm{~mm}$ (Table 1) this result disagreement with [8] that Pupal period of A. convolvuli was observed to vary from 12 to18 days with an average of $14.45 \pm 2.71$ days. The sex of the adult can be recognizes through watching the Pupa, there are two small points at the fifth segment of the male, while in females this feature appears as a line.

4-1 Total life cycle: Under laboratory conditions the spruge hawk moth completed its one generation (egg to adult) in (70 - 103) days with an average of $89.5 \pm 10.1$ days. First generation larvae can be found in April; a second generation occurs during late September and October, this result disagrees with [2], Who found that First-generation larvae can be found during June; if a second generation occurs, it will be in August .

5- Adult: Emergence of the adults usually occurred during night and rare at day time. Immediately after the emergence a brownish thick fluid oozed out from the anus of pupae in both sexes. Soon after the emergence moths were inactive and sluggish for some time. Its body is olive brown with white and black markings. The forewings are patterned with olive brown; the hind wings are pink with black markings. It is readily distinguished which is predominately pink. The longevity of the female ranged from 11-16 days with an average of $13.86 \pm 1.73$ While in case of male it was 8-11 days with an average of $10.55 \pm 1.00$, this result is somewhat in co firmly with [8] Longevity of $A$. convolvuli adults ranged from 10 to 12 days with an average of $11.3 \pm 0.82$ days and 13 to 16 days with an average of $14.3 \pm 0.94$ days in case of male and females.

5-1 Copulation: Mating was observed during night hours a day or two after emergence. Eggs were laid individually or in cluster during night hours on the spruge leaves or on the sides of the cages in the absence of the host. The adults lived for about 3 to 5 days after completing oviposition.

\section{FIGURES AND TABLES}

Table 1 Growth parameter of Hyles euphorbia on leafy spruge

\begin{tabular}{|c|c|c|c|c|c|c|c|c|c|c|c|c|}
\hline \multirow{2}{*}{ Stage } & \multicolumn{6}{|c|}{ Length $(\mathrm{mm})$} & \multicolumn{6}{|c|}{ Head capsule width (mm) } \\
\hline & \multicolumn{3}{|c|}{ Range } & \multicolumn{3}{|c|}{ Average } & \multicolumn{3}{|c|}{ Range } & \multicolumn{3}{|c|}{ Average } \\
\hline \multicolumn{13}{|c|}{ Larvae } \\
\hline I & 3.70 & - & 7.40 & 5.97 & \pm & 1.18 & 0.76 & - & 0.78 & 0.77 & \pm & 0.01 \\
\hline II & 12.00 & - & 18.00 & 15.51 & \pm & 2.04 & 1.16 & - & 1.31 & 1.26 & \pm & 0.04 \\
\hline III & 22.00 & - & 27.50 & 25.08 & \pm & 1.62 & 1.91 & - & 1.99 & 1.95 & \pm & 0.02 \\
\hline IV & 46.00 & - & 58.00 & 50.16 & \pm & 3.85 & 3.00 & - & 3.10 & 3.06 & \pm & 0.05 \\
\hline $\mathrm{V}$ & 85.00 & - & 99.00 & 94.60 & \pm & 4.03 & 5.00 & - & 5.20 & 5.05 & \pm & 0.08 \\
\hline Pre-Pupa & 80.00 & - & 85.00 & 82.92 & \pm & 1.36 & & & & & & \\
\hline Pupa & 50.00 & - & 55.00 & 52.67 & \pm & 1.65 & & & & & & \\
\hline
\end{tabular}

Table 2 Average larval period of Hyles euphorbia on leafy spruge

\begin{tabular}{|c|c|ccc|ccc|}
\hline \multirow{2}{*}{$\begin{array}{c}\text { Stage } \\
\text { number. }\end{array}$} & \multirow{2}{*}{ Instars } & \multicolumn{5}{|c|}{ Duration (days) } \\
\cline { 3 - 8 } & & \multicolumn{3}{|c|}{ Range } & \multicolumn{3}{c|}{ Average } \\
\hline 1 & I & 4.0 & - & 5.0 & 4.56 & \pm & 0.35 \\
\hline 2 & II & 2.0 & - & 3.0 & 2.54 & \pm & 0.39 \\
\hline 3 & III & 2.0 & - & 3.0 & 2.58 & \pm & 0.37 \\
\hline 4 & IV & 3.0 & - & 5.0 & 4.10 & \pm & 0.63 \\
\hline 5 & V & 6.0 & - & 7.0 & 6.53 & \pm & 0.34 \\
\hline
\end{tabular}


Table 3 Biology of Hyles euphorbia on leafy spruge

\begin{tabular}{|l|rll|rll|}
\hline \multirow{2}{*}{\multicolumn{1}{|c|}{ Stage. }} & \multicolumn{4}{c|}{ Duration of stage (in days) } \\
\cline { 2 - 5 } & \multicolumn{3}{|c|}{ Range } & \multicolumn{2}{c|}{ Average } \\
\hline Egg period & 7.0 & - & 12.0 & 9.42 & \pm & 1.65 \\
\hline Larval Period & 17.0 & - & 23.0 & 20.31 & \pm & 2.08 \\
\hline Prepupa period & 2.0 & - & 3.0 & 2.67 & \pm & 0.37 \\
\hline pupa period & 44.0 & - & 65.0 & 57.10 & \pm & 5.97 \\
\hline Total Life Cycle & 70.0 & - & 103.0 & 89.5 & \pm & 10.1 \\
\hline
\end{tabular}

\section{CONCLUSION}

The leafy spruge moth, H. euphorbiae Linnaeus is one of the main insects which present on Euphorbia macrocalda. Biology was studied under laboratory conditions. The development of egg, larva, pre-pupa and pupal periods occupied $9.42 \pm 1.65,20.31 \pm 2.08,2.67 \pm 0.37$ and $57.10 \pm 5.97$ days respectively. The longevity of adult ranged from 8-11 days and 11 to 16 days in case of male and female. Total life cycle ranged from 70 to 103 days. Accurate information on the biology of $H$. euphorbiae is a prerequisite for developing an effective pest management programme against genus euphorbiae. The results of the experiments described here have resolved development times in Kurdistan Region of Iraq.

\section{REFERENCES}

[1] A.K. Hundsdoerfer, I.J. Kitching, and M. Wink, The phylogeny of the Hyles-euphorbiae-complex (Lepidoptera: Sphingidae): molecular evidence from sequence data and ISSR-PCR fingerprints. Org. Divers Evol., 5, 2005, $173-198$.

[2] N.H. Poritz, Laboratory fecundity and development, field population dynamics, pupil predation and the history of releases of the spurge hawkmoth, Hyles euphorbiae (L.), a biological control agent of leafy spurge, Euphoria esula L., in Montana. MSc. Thesis, Deptartment of Entomology, Montana State University, Bozeman, MT: , 1998, 92. (Write the Web Site).

[3] F.L. Leistritz, D.A. Bangsund, and N.M. Hodur, Assessing the economic impact of invasive weeds: The case of leafy spurge (Euphorbia esula). Weed Technology, 18, 2004, 1392- 1395.

[4] F.J. Evans, and C.J. Soper, The tigliane, daphnane and ingenane diterpenes, their chemistry, distribution and biological activities. A review. Lloydia, 41, 1978, 193-233.

[5] A.K. Hundsdoerfer, J.N. Tshibangu, B. Wetterauer and M. Wink, Sequestration of phorbol esters by aposematic larvae of Hyles euphorbiae (Lepidoptera: Sphingidae). Chemoecology, 15, 2005, 261-267.

[6] E.P. Wiltshire, The Lepidoptera of Iraq.Aldar ana Son.Bartholomew Press,Darking., 1957, 162.

[7] Y. Karimipoor, Y. Fathipour, A.A. Talebi, and S. Moharamipour, Biology of Hyles euphorbiae (Lep., Sphingidae) on weedy spurges and determination of its parasitoids in west Azerbaijan, Iran. Iranian Journal of agricultural Science, 37(4), $2006,727-735$.

[8] M. Chandaragi, Survey and surveillance of green gram sphingid, Agrius convolvuli (Linnaeus) (Lepidoptera: Sphingidae) and its management. University of Agricultural Sciences, Dharwad, JUNE, 2010.

[9] T.M. Leong, and K.K.P. Lim, Final instar caterpillar and metamorphosis of hawk moth, Theretra nessus (Drury) in Singapore (Lepidoptera: Sphingidae :Macroglossinae). Nature in Singapore, 2, 2009, 503- 510. 